\title{
Impact of COVID-19 pandemic on patients with rheumatic diseases in Latin America
}

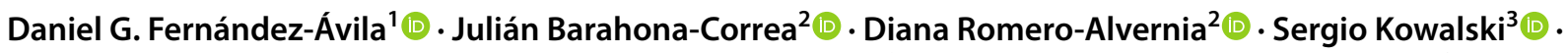

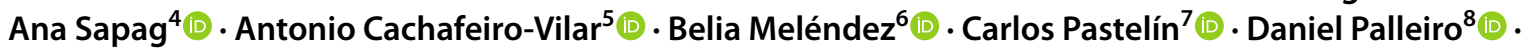

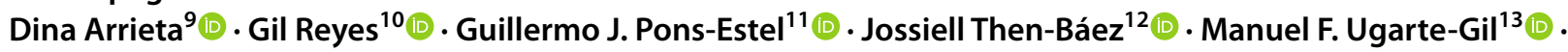

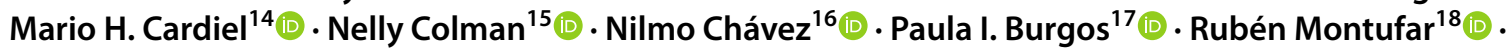 \\ Sayonara Sandino ${ }^{19}$ (D) Yurilis J. Fuentes-Silva ${ }^{20}$ (Enrique R. Soriano ${ }^{21} \mathbb{C}$
}

Received: 1 July 2021 / Accepted: 25 September 2021 / Published online: 5 November 2021

(c) The Author(s), under exclusive licence to Springer-Verlag GmbH Germany, part of Springer Nature 2021

\begin{abstract}
The objective of our study was to describe knowledge, attitudes and practices of Latin-American rheumatology patients regarding management and follow-up of their disease during COVID-19 pandemic. A cross-sectional observational study was conducted using a digital anonymous survey. Rheumatic patients $\geq 18$ years from non-English-speaking PANLAR countries were included. Our survey included 3502 rheumatic patients living in more than 19 Latin-American countries. Median age of patients was 45.8(36-55) years and the majority (88.9\%) was female. Most frequently self-reported disease was rheumatoid arthritis (48.4\%). At least one anti-rheumatic treatment was suspended by $23.4 \%$ of patients. Fear of contracting SARS-Cov2 (27.7\%) and economic issues (25\%) were the most common reasons for drug discontinuation. Self-rated disease activity increased from 30 (7-50) to $45(10-70)$ points during the pandemic. Communication with their rheumatologist during the pandemic was required by $55.6 \%$ of patients, mainly by telephone calls $(50.2 \%)$ and social network messages $(47.8 \%)$. An adequate knowledge about COVID-19 was observed in 43\% of patients. Patients with rheumatic diseases in Latin America were negatively affected by the COVID-19 pandemic. An increase in self-rated disease activity, a reduction in medication adherence, and hurdles for medical follow-up were reported. Teleconsultation was perceived as a valid alternative to inperson visits during the pandemic.
\end{abstract}

Keywords COVID-19 $\cdot$ Rheumatology $\cdot$ Telehealth $\cdot$ Adherence $\cdot$ Knowledge $\cdot$ Behavior

\section{Introduction}

At the end of 2019, a new respiratory viral disease broke out in Wuhan, China. The viral agent was named SARSCoV-2 (Severe Acute Respiratory Syndrome Coronavirus 2) and COVID-19 (Coronavirus disease 2019) was the name assigned to the condition. It rapidly spread across the globe, and in March 2020 the World Health Organization (WHO) declared it a pandemic and a major global health threat [1-3].

Since then, preventive measures taken around the world have aimed at reducing the risk of infection and the effects of COVID-19. These measures mainly focus on social

Daniel G. Fernández-Ávila

daniel.fernandez@javeriana.edu.co

Extended author information available on the last page of the article isolation, hygiene practices, social distancing, and wearing a mask when people get together [4-6].

Social isolation imposed through lockdowns, quarantines and curfews as preventive measures of virus expansion during the pandemic has undermined follow-up of patients with rheumatic diseases. These patients face a critical dilemma between the risk of exposure as a vulnerable population and the need of medical attention. Considering that rheumatic patients constitute a potentially immunosuppressed and vulnerable population, changes in behaviors, attitudes and risk perception were expected [7-9].

During previous pandemics, factors associated with differential behaviors have been identified, including lack of knowledge, false beliefs and self-perception of risk. Knowledge, attitudes, and behaviors were thoroughly study to investigate patterns of community reactions to a disease [10-16]. 
Limited access to health-care services and in-person visits due to social restrictions highlighted the importance of self-management in chronic rheumatic diseases. Self-management of disease, defined as the knowledge and strategies to effectively daily care of chronic conditions, appeared as a crucial topic in the long-term care of chronic diseases.

Social support networks also played a role in the application of self-care strategies, which could be positive or negative depending on the type of interaction. The factors that reinforce self-care include emotional support by family and friends, and assistance to fulfill personal, financial or care needs[18, 19].

Regarding adherence to drug treatments, some studies evaluated adherence and self-efficacy in patients with RA. Self-efficacy was defined as an individual's belief in their ability to follow drug regimens to achieve improved health outcomes [17-20]. It was reported that determining factors for an adequate adherence include self-efficacy, the severity of the disease, adverse effects, the confidence or fear of medication, and the physician-patient relationship [20]. The use of telehealth systems, widely spread after COVID19 outbreak, may have an additional still not well-known impact on efficacy and adherence to rheumatologic treatment [21-24].

These factors suggest that an unexpected event such as the COVID-19 pandemic, with a great impact on the activities of the general population, has the potential to alter the management and follow-up related behaviors of patients with rheumatic diseases.

Therefore, the objective of our study was to explore the knowledge, attitudes, and behaviors of rheumatic patients in Latin America during the COVID-19 pandemic. The original survey designed by our group covered the impact of COVID-19 on both rheumatic patients and rheumatologists. Only patients' results will be presented in this paper.

\section{Methods}

\section{Design}

We conducted a cross-sectional observational study by means of an anonymous digital survey using RedCap ${ }^{\circledR}$ (Research Electronic Data Capture), a free web platform for building online surveys and databases. Design and procedures followed current recommendations for survey-based studies [25, 26].

\section{Patients}

We included patients over 18 years old from Spanish or Portuguese-speaking PANLAR (Pan American League of
Rheumatology Associations) countries with at least one selfreported immune-mediated rheumatic disease.

\section{Survey procedures}

The online survey was sent to leading rheumatologists of each PANLAR country to spread the survey among colleagues and retrieve information about their patients. A sixty-day period was established to allow data collection throughout June and July 2020. Convenience sampling method was used, so the sample size was not determined in advance. The RedCap platform was also used for data storage.

\section{Survey structure and content}

A self-report instrument was developed based on previous experiences and recommendations [9-16]. The survey assessed demographic and clinical information, diseases and comorbidities, use of medications, confirmed diagnosis of COVID-19, symptoms suggestive of COVID-19 (in patients without confirmed diagnosis), and request for medical consultation or hospitalization. Since data were self-reported, researchers did not have access to confirmatory evidence.

Patients were evaluated using a set of answer options such as "Yes", "No", "Don't know/no answer", a Likert scale, or answers with specific values (eg, a 0-100 points scale). For some questions, the respondents could provide more than one answer (eg, comorbidities or medications). The survey was developed in Spanish and later translated to Portuguese by a Brazilian researcher (SK).

The following domains were specifically explored:

Knowledge: Questions aimed at evaluating knowledge of disease features, modes of transmission, available therapies, and sources of information.

Attitudes: Questions assessed level of agreement with the recommendations for individual and social care, efficacy of self-management and self-adjustment of drug dosage. Perceived risk and the ease of communication through digital and remote means were evaluated. The willingness to adopt alternatives to face-to-face medical consultation were also explored.

Behaviors: Questions explored behavioral changes adopted to guarantee the continuity of medical treatment, adherence and persistence to medical recommendations.

\section{Statistics}

Descriptive statistics were performed by calculating measures of central tendency for quantitative variables and using counts and percentages for qualitative and nominal variables. 


\section{Ethics}

The study was conducted according to the principles of the Declaration of Helsinki and the Resolution 8430/1993 of the Colombian Health Ministry. By the same Resolution, our study was considered a risk-free investigation. The study was approved by the Research and Ethics Committee of the Hospital Universitario San Ignacio and the Pontificia Universidad Javeriana (Approval 2020/106). All responses were anonymous and self-reported, and confidentiality of data was maintained by means of secure databases.

\section{Validation and pilot testing}

Initially, a pilot survey was conducted in Bogotá, Colombia, to validate the usefulness and convenience of the questionnaires. Subsequently, the survey method was adjusted according to identified difficulties before the generalized application of the instrument in PANLAR countries.

\section{Results}

Our study included 3502 rheumatic patients from more than 19 Latin-American countries. The countries that contributed the largest number of respondents were Chile (549 respondents; $15.7 \%)$, Mexico (528; 15.1\%), Colombia (311; 8.9\%), Venezuela (304; 8.7\%), Brazil (293; 8.4\%), and El Salvador $(289 ; 8.2 \%)$. The number and percentage of respondents per country can be seen in Table 1 .

Median (IQR, interquartile range) age of respondents of the total sample was 45.8 (36-65) years, and 3113 (88.9\%) were female. Most patients reported to be married (1578; $45.1 \%$ ) while 1225 (35\%) patients claimed to be single. Regarding education level, most patients reported a graduate (1457 respondents; $41.6 \%)$ or technician level $(648 ; 18.5 \%)$. Occupation of patients was widely variable, but office workers (mostly intellectual work) were the largest part among the sample (522 respondents; $14.9 \%$ ). Having children in charge was recognized by $1751(50 \%)$ of those surveyed. Other demographic, educational and occupational data can be seen in Table 2.

Rheumatoid arthritis was the most common self-reported disease (1694 patients; 48.4\%) followed by systemic lupus erythematosus $(1012 ; 28.9 \%)$. Table 3 shows the number and percentage of rheumatic diseases of those surveyed.

Median (IQR) disease activity during the month prior to the pandemic, on a $0-100$ points, was self-rated $30(7-50)$ by respondents. On the same scale, median (IQR) disease activity during pandemic was self-rated 45 (10-70).

Patients were asked about all the treatments they were receiving, so they could mark all options that applied. Antimalarials (1172 patients; 33.5\%), prednisone (1091;
Table 1 Number and percentage of rheumatic patients that responded to the survey in each country

\begin{tabular}{lc}
\hline Country & Number $(\%)$ \\
\hline Argentina & $198(5.6)$ \\
Bolivia & $30(0.9)$ \\
Brazil & $293(8.4)$ \\
Chile & $549(15.7)$ \\
Colombia & $311(8.9)$ \\
Costa Rica & $90(2.6)$ \\
Cuba & $46(1.3)$ \\
Ecuador & $99(2.8)$ \\
El Salvador & $289(8.2)$ \\
Guatemala & $22(0.6)$ \\
Honduras & $103(2.9)$ \\
Mexico & $528(15.1)$ \\
Nicaragua & $36(1)$ \\
Panama & $79(2.3)$ \\
Paraguay & $45(1.3)$ \\
Peru & $244(7)$ \\
DominicanRepublic & $156(4.4)$ \\
Uruguay & $42(1.2)$ \\
Venezuela & $304(8.7)$ \\
Other & $38(1.1)$ \\
\hline
\end{tabular}

Table 2 Marital status, education level and occupational data selfreported by participants $(N=3502)$

\begin{tabular}{lc}
\hline Domain & $n(\%)$ \\
\hline Marital status & \\
Married & $1578(45.1)$ \\
Single & $1225(35)$ \\
Living with a partner-not married & $303(8.6)$ \\
Widow/widower & $135(3.8)$ \\
Other & $261(7.4)$ \\
Education & \\
Elementary & $225(6.4)$ \\
High school & $613(17.5)$ \\
Technician & $648(18.5)$ \\
Graduate & $1457(41.6)$ \\
Postgraduate & $479(13.7)$ \\
Other & $80(2.3)$ \\
Occupation & \\
Student & $156(4.4)$ \\
Office (mostly intellectual) & $522(14.9)$ \\
Mostly manual chores & $147(4.2)$ \\
Both manual and intellectual & $362(10.3)$ \\
Health worker & $393(11.2)$ \\
Unemployed & $494(14.1)$ \\
Retired & $529(15.1)$ \\
Other & $899(25.7)$ \\
\hline
\end{tabular}


Table 3 Number and percentage of self-reported rheumatic diseases*

\begin{tabular}{lc}
\hline Rheumatic disease & $n(\%)$ \\
\hline Rheumatoid arthritis & $1694(48.4)$ \\
Systemic lupus erythematosus & $1012(28.9)$ \\
Sjögren's syndrome & $384(11)$ \\
Other rheumatic disease & $242(6.9)$ \\
Ankylosing spondylitis & $184(5.2)$ \\
Other inflammatory arthritis & $144(4.1)$ \\
Psoriatic arthritis & $125(3.6)$ \\
Antiphospholipid syndrome & $116(3.3)$ \\
Systemic sclerosis & $98(2.8)$ \\
Inflammatory myositis & $58(1.7)$ \\
Other spondyloarthritis & $58(1.7)$ \\
Mixed connective tissue disease & $57(1.6)$ \\
Ocular inflammation & $55(1.6)$ \\
Juvenile arthritis & $53(1.5)$ \\
Polymyalgia rheumatica & $35(1)$ \\
ANCA-associated vasculitis & $27(0.8)$ \\
Undifferentiated connective tissue disease & $22(0.6)$ \\
Gout & $21(0.6)$ \\
Other vasculitides & $14(0.4)$ \\
Behçet's disease & $9(0.3)$ \\
Giant cell arteritis & $6(0.17)$ \\
IgG-4-related disease & $5(0.1)$ \\
Sarcoidosis & $3(0.08)$ \\
\hline
\end{tabular}

*Patients could mark more than one answer

$31.1 \%)$, and methotrexate $(1002 ; 28.6 \%)$ were the most commonly self- reported agents, followed by leflunomide (436; 12.4\%), azathioprine (322; 9.2\%), mycophenolate mophetil $(293 ; 8.4 \%)$, and sulfasalazine $(260 ; 7.4 \%)$.

The presence of comorbidities was self-reported by $1850(52.3 \%)$ respondents. The most common selfreported comorbidities were hypertension (669 patients; $19.1 \%)$ and depression/anxiety $(455 ; 13 \%)$.

Most commonly reported treatments for comorbidities weresleepmedicines (718 respondents; 20.5\%) and angiotensin II receptor blockers $(465,13.3 \%)$.

Regarding access to medication during the pandemic, a majority of patients reported that they received antirheumatic medication through health insurance (1545 respondents; $44.1 \%)$, while 920 (26.3\%) patients claimed to have purchased the medication themselves.

The majority of patients claimed that they clearly knew how to take anti-rheumatic medication $(3278 ; 93.6 \%)$. There were 862 patients who reported they were clearly aware about adverse effects (862 patients; $24.6 \%$ ) of the drugs, and how to adjust drug doses in case of flare (1315; $37.5 \%)$.

At least one anti-rheumatic medication was suspended by 819 (23.4\%) patients of the total sample. From these, 240 patients (29.3\%) suspended antimalarials and 149 (18.2\%) discontinued methotrexate.

From 819 patients that suspended the anti-rheumatic medication, 227 (27.7\%) stated that the decision was based on the fear that the medication might increase the chance of contracting SARS-Cov2 infection. Other patients claimed that the reason for drug treatment interruption was that they could not buy it due to economic issues (205 patients; 25\%) or that the drug was not dispensed by the health insurance (152 patients; $18.6 \%$ ).

At least one medication for comorbidities was also suspended by 291 (15.7\%) patients. The drugs most frequently reported by patients as discontinued were neuropathic analgesics, non-steroidal anti-inflammatory drugs (NSAIDs), and psychiatric drugs. The reasons for discontinuation were similar to those reported for anti-rheumatic drugs.

A diagnosis of COVID-19 was given to 109 (3.1\%) patients. Of those, 13 (11.9\%) were hospitalized but none required mechanical ventilation. The most frequently selfreported symptoms were fatigue, fever, cough, dysgeusia and dysosmia.

A communication with the rheumatologist without prior appointment was considered highly probable during the pandemic by 1413 (40.3\%) patients. There were 1066 (30.4\%) patients that canceled a medical appointment on their own and 1487 (42.5\%) who were cancelled. Of the latter, 481 $(32.3 \%)$ patients were offered an alternative to the face-toface visit. Of these, telehealth consultation was accepted by 440 (91.5\%) patients; 240 (49.9\%) made the consult by telephone call, 175 (36.4\%) by video call, and $111(23.1 \%)$ by other means. Re-scheduling of medical visits was reported by 1007 patients $(28.7 \%)$ and $10(2.1 \%)$ received a face-toface visit at home.

The median (IQR) percentage of satisfaction with these behavioral changes for medical communication (on a scale of $0-100$ points) was $90(70-100)$.

There were 1948 (55.6\%) patients who required to communicate with their rheumatologists during the pandemic. From these, an effective interpersonal communication was reported by $1415(72.6 \%)$ patients. Telephone calls and text messages were the most frequently means of communication (Table 4).

The use of telehealth systems was considered a valid strategy by $2950(84.2 \%)$ patients during the pandemic, and $1880(53.7 \%)$ considered that its use would also be valid after the pandemic.

Regarding knowledge about COVID-19, 1530 (43.7\%) patients demonstrated an adequate level of understanding about modes of transmission, lethality and current treatments. Main source of information was television (2358 respondents) followed by social networks and official websites like WHO, Centers for Disease Control (CDC), or Ministry of Health websites (Table 5). 
Table 4 Means of communication used for medical care during the pandemic $(N=1948)$

\begin{tabular}{ll}
\hline Means of communication & $n(\%)$ \\
\hline Telephone call & $978(50.2)$ \\
Text messages (Whatsapp, text message, other) & $931(47.8)$ \\
E-mail & $314(16.1)$ \\
Telehealth & $265(13.6)$ \\
Other & $161(8.3)$ \\
Home medical consultation & $29(1.5)$ \\
\hline
\end{tabular}

Table 5 Main sources of information about SARS-CoV-2 or COVID19 pandemic used by respondents $(N=3502)$

\begin{tabular}{lc}
\hline Sources of information & $n(\%)$ \\
\hline Television & $2358(67.3)$ \\
Social networks (Facebook, Twitter) & $1965(56.1)$ \\
Official websites (CDC, WHO) & $1776(50.7)$ \\
Health worker & $1228(35.1)$ \\
Radio & $661(18.9)$ \\
Friends and family & $571(16.3)$ \\
Newspaper & $568(16.2)$ \\
Internet videos (Youtube) & $552(15.8)$ \\
Non-official websites & $350(10)$ \\
Other & $76(2.2)$ \\
\hline
\end{tabular}

Daily living was perceived disrupted by 2995 (85.5\%) patients. The risk of becoming infected with SARS-CoV-2 during the pandemic was perceived as high or very high by $862(24.6 \%)$ patients for themselves and also for their relatives (697 respondents; 19.9\%).

Adherence to precaution measures, such as avoiding public gatherings, wearing face masks, and frequent hand washing was adequate for 2724 (77.8\%) respondents.

Social isolation due to disruption of daily living was considered a major problem by $981(28 \%)$ patients and a minor problem by $1086(31 \%)$, while $1236(35.3 \%)$ respondents stated that for them this was not a problem at all.

Social isolation due to the pandemic generated emotional issues in 2023 (57.8\%) patients. Other self-reported issues generated by social isolation are shown in Table 6 .

\section{Discussion}

Our survey retrieved data from 3502 rheumatic patients living in more than 19 Latin-American countries. Median age of patients was 45.8 years and the majority (88.9\%) was female. Most frequently self-reported rheumatic diseases were rheumatoid arthritis, systemic lupus erythematosus, psoriatic arthritis, juvenile arthritis, and ankylosing
Table 6 Self-reported issues generated by social isolation $(N=3502)$

\begin{tabular}{lc}
\hline Issues & $n(\%)$ \\
\hline Emotional issues & $2023(57.8)$ \\
Issues to access to medical care or medication & $1058(30.2)$ \\
Lack of communication with family members & $975(27.8)$ \\
Unemployment & $790(22.6)$ \\
Other & $357(10.2)$ \\
Issues to obtain food or water & $209(6)$ \\
\hline
\end{tabular}

spondylitis.During the pandemic, approximately one quarter of patients discontinued their anti-rheumatic treatment, and antimalarials and methotrexate were the most commonly discontinued drugs.

More than half of patients had comorbidities. The most frequent comorbidities were hypertension and psychiatric disorders (depression/anxiety). Similarly, almost $16 \%$ of patients interrupt comorbidities drug treatment during the pandemic. The most common self-reported reasons for drug discontinuation were the fear that the anti-rheumatic medication might increase the chance of contracting SARS-Cov2 infection and economic issues.

In a study of the impact of SARS-CoV-2 infection in 332 patients with systemic lupus erythematosus, drug discontinuation appeared as an important cause of disease flare [26].In this study, the correlation between flare and discontinuation of therapy was statistically significant. The researchers suggested that treatment interruption should be avoided or considered cautiously on the basis of comorbidities and individual infection risk [26].

In a French survey with 655 respondents, more than $30 \%$ of the patients suspended or decreased the dosage of one of their drugs during the lockdown period. This was followed in $63.4 \%$ of them by increased disease activity, and drug treatment modifications were mostly motivated by fear of SARS-CoV-2 contagion (79.3\%) [27].

When asked about self-management of disease, a majority of patients of our survey reported that they clearly knew how to take their medication, the adverse effects of drugs, and how to adjust drug doses in the event of a flare. Self-management is defined by Grady et al. as the daily management of chronic conditions by individuals over the course of an illness [17]. The management models for these diseases have evolved towards a current paradigm in which patients play a fundamental role in guiding their own care together with their health providers. This concept encompasses most chronic disease, including rheumatic conditions. These diseases share similar challenges for patients, including management of symptoms and limitations, monitoring of physical changes, management of medications and complex regimens, adequate nutrition and physical activity, adaptation to social and 
psychological demands, and interaction with health-care providers [18-20].

In our survey, 109 (3\%) of patients get infected with SARS-Cov2. In a study conducted by Costantino et al. that included 655 patients with chronic inflammatory rheumatic diseases, the incidence of COVID-19 was 6.9\%. Five patients needed to be hospitalized and no death was observed; the population was predominantly female $(61.8 \%)$ with a mean age of 51 years [27].

In a study conducted by Zucchi et al., from 332 enrolled patients 6 patients (1.8\%) tested positive for SARS-CoV-2 infection. The incidence of positive COVID-19 was significantly higher in the subgroup of patients treated with biological Disease-Modifying Anti-Rheumatic Drugs (DMARD) [26].

As our main objective was to illustrate the impact of the pandemic on patients with a wide arrange of rheumatic diseases in our region, we decided to explore whether selfperceived disease activity increased during the pandemic, compared to the month prior to the pandemic. Although, a number of Patient-Reported Outcome Measures are available for different rheumatic diseases, [28] we considered that a generic visual analog scale about self-perceived activity would show this phenomenon; a similar approach has been used in previously published survey studies [29].

In our study, most of respondents used telehealth when it was offered, mainly through telephone calls and video calls. When patients required to communicate with their rheumatologist during pandemic, two thirds achieved an effective communication, mainly by telephone calls and text messages through WhatsApp or other social networks. Although 84\% of responders considered teleconsultation as a valid strategy during the pandemic, this proportion diminished to 53\% as a hypothetical alternative after the pandemic.

Gkrouzman et al. stated that the COVID-19 outbreak affected the delivery of rheumatology services at an unprecedented level[21]. Before the COVID-19 pandemic, teleconsultation was proposed only to rheumatology patients who needed specialist care but lived in remote areas. Although telemedicine has been available for several rheumatology services previously, the pandemic dramatically accelerated its use. According to most researchers, despite the fact that in-person rheumatology visits were generally reinstate, the use of telemedicine services is expected to remain widespread in coming years [21-24]. In contrast, in our study 2950 (84.2\%) patients considered that the use of telehealth was valid during the pandemic, but this number decreased to $1880(53.7 \%)$ when patients were asked if they considered that the use of telehealth would be valid after the pandemic.

In Australia, Zhu et al. conducted a large survey on 3040 rheumatic patients (54 years, $69 \%$ females) to determine the impact of telehealth on patient care throughout 2020 [27]. Telehealth use during the COVID-19 pandemic was associated with improved appointment attendance, but with diagnostic delay and reduced likelihood of changing existing immunosuppressive therapy. Authors stated that although the effects of telehealth cannot be distinguished from changes in practice due to the pandemic, these findings suggest that telephone-based telehealth may have a negative impact on the appropriateness of management of rheumatology patients [30].

An adequate knowledge on COVID-19 was found in 43\% of our patients and the main sources of information were television and official websites. A survey by Hassen et al. found that patients' knowledge about COVID-19 was specially correlated with social media use. In this cross-sectional study, patients' perceptions of worsened disease activity were correlated with unplanned health-care visits, medication nonadherence, and hurdles accessing drugs [31].

Regarding self-perception of risk, around a quarter of patients perceived a high or very high risk of being infected during the pandemic, either for themselves or for their families. A positive attitude and an adequate adherence to general precautions to avoid COVID-19 was reported by three quarters of our respondents.

COVID-19 surged as an unprecedented event that has disrupted patient lives and led to a rise in the incidence of mental health disorders. Lockdowns, quarantines, social distancing constraints, and fear of contracting the disease also drive behavioral changes. In our survey, a large majority of patients reported a disruption in daily living due to social restrictions. From the patient perspective, the impact of the pandemic on health care was remarkable. Preventive measures, especially social isolation, transformed their healthcare and daily living behaviors. A study on 637 rheumatic patients' perceptions and behaviors conducted by Hassen et al. found that the COVID-19 pandemic and public health measures significantly affected rheumatic patients' health management, which contributes to disease flare-up [31].

Due to the economic and social devastation due to COVID-19, many patients may be at an increased risk of having difficulty to access to medical care, accentuated stress, and worsening of mental health disorders, such as anxiety or depression. A recent review by Bathia et al. found that there was a significant association between COVID19 pandemic and the adverse impact on the mental health and daily living activities in rheumatology patients [32]. In our survey, $14.1 \%$ (41) of the patients who were receiving psychiatric medication to treat their comorbidities had to discontinue it.

Our study has some limitations. The patient questionnaire was developed de novo, based on available literature and practice experience. Nevertheless, it was validated by an independent scientific committee and previously tested for readability, acceptability and timing in a pilot study conducted in Colombia. 
All data were self-reported by patients, which may produce recall bias. Nevertheless, the number of respondents from 19 different countries seems to ensure that our study satisfactorily reflects the reality of the impact of COVID-19 pandemic on Latin-American rheumatology patients.

Given that the survey was distributed by PANLAR members, selection bias may be present. Nonetheless, as PANLAR gathers the national rheumatology societies of each of the member countries, we consider that the Latin-American rheumatology patient population was adequately represented in our survey.

Finally, we could not control for every possible lifestyle factor, attitude or behavior in our survey, and the cross-sectional observational nature of the design leaves the possibility of undetected problems in a rapidly changing situation such as a pandemic.

\section{Conclusion}

COVID-19 appeared unexpectedly as an event that has disrupted patient lives, affecting daily activities as well as health-care related behaviors. Patients with rheumatic diseases in Latin America were negatively affected by the COVID-19 pandemic. An increase in disease activity, a reduction in medication adherence, and problems for medical follow-up were frequently self-reported. A large majority ofpatients considered that teleconsultation was as a valid alternative to face-to-facevisits during the pandemic.

Acknowledgements Editorial assistance was provided by Content Ed Net, Madrid, Spain.

Author contributions All authors have contributed significantly to the conception, design, or acquisition of data, or analysis and interpretation of data. All authors have participated in in drafting, reviewing, and/or revising the manuscript and have approved its submission.

Funding This study was supported by an unrestricted grant from Pan American League of Rheumatology Associations (PANLAR).

Data availability The data that support the findings of this study are available from the corresponding author upon reasonable request.

\section{Declarations}

\section{Conflict of interests None.}

Ethical approval The study was approved by the Research and Ethics Committee of the Hospital Universitario San Ignacio and the Pontificia Universidad Javeriana (Approval 2020/106).

Consent to participate The survey was sent via online and voluntarily completed.

Consent for publication Not applicable.

\section{References}

1. Harapan H, Itoh N, Yufika A, Winardi W, Keam S, Te H, Megawati D, Hayati Z, Wagner AL, Mudatsir M (2020) Coronavirus disease 2019 (COVID-19): a literature review. J Infect Public Health 13:667-673. https://doi.org/10.1016/j.jiph.2020.03.019

2. Patel A, Jernigan DB (2020) Initial public health response and interim clinical guidance for the novel coronavirus outbreakUnited States, December 31, 2019-February 4, 2020. MMWR Morb Mortal Wkly Rep 69:140-146. https://doi.org/10.15585/ mmwr.mm6905e 1

3. Saavedra Trujillo CH (2020) Consenso colombiano de atención, diagnóstico y manejo de la infección por SARS-COV-2/ COVID 19 en establecimientos de atención de la salud. Recomendaciones basadas en consenso de expertos e informadas en la evidencia. Infectio 24:1-102

4. Yang P, Qi J, Zhang S, Wang X, Bi G, Yang Y et al (2020) Feasibility study of mitigation and suppression strategies for controlling COVID-19 outbreaks in London and Wuhan. PLoS ONE 15:e0236857. https://doi.org/10.1371/journal.pone.02368 57

5. Mehrotra A, Ray K, Brockmeyer DM, Barnett ML, Bender JA (2020) Rapidly converting to "virtual practices": outpatient care in the era of Covid-19. NEJM Catal Innov Care Deliv. https:// doi.org/10.1056/CAT.20.0091

6. Lee TH (2020) Creating the new normal: the clinician response to Covid-19. NEJM Catal Innov Care Deliv. https://doi.org/10. 1056/CAT.20.0076

7. Figueroa-Parra G, Aguirre-Garcia GM, Gamboa-Alonso CM, Camacho-Ortiz A, Galarza-Delgado DA (2020) Are my patients with rheumatic diseases at higher risk of COVID-19? Ann Rheum Dis 79:839-840. https://doi.org/10.1136/annrh eumdis-2020-217322

8. Favalli EG, Ingegnoli F, De Lucia O, Cincinelli G, Cimaz R, Caporali R (2020) COVID-19 infection and rheumatoid arthritis: faraway, so close! Autoimmun Rev. https://doi.org/10. 1016/j.autrev.2020.102523

9. Saldarriaga Rivera LM, Fernández Ávila D, Bautista Molano W, Jaramillo Arroyave D, Bautista Ramírez AJ, Díaz Maldonado A et al (2020) Recommendations on the management of adult patients with rheumatic diseases in the context of SARS-CoV-2/ COVID-19 infection Colombian Association of Rheumatology. Reumatol Clin 16:437-446. https://doi.org/10.1016/j.reuma. 2020.06.011

10. Guidry JPD, Carlyle KE, LaRose JG, Perrin P, Messner M, Ryan M (2019) Using the health belief model to analyze Instagram posts about Zika for public health communications. Emerg Infect Dis 25:179-180. https://doi.org/10.3201/eid2501.180824

11. Bults M, Beaujean DJ, Richardus JH, Voeten HA (2015) Perceptions and behavioral responses of the general public during the 2009 influenza A (H1N1) pandemic: a systematic review. Disaster Med Public Health Prep 9:207-219. https://doi.org/10. 1017/dmp.2014.160

12. Lin Y, Huang L, Nie S, Liu Z, Yu H, Yan W (2011) Knowledge, attitudes and practices (KAP) related to the pandemic (H1N1) 2009 among Chinese general population: a telephone survey. BMC Infect Dis 11:128. https://doi.org/10.1186/1471-2334-11-128

13. Ávila J, Munayco CV, Gómez J, Nunura J, Canahuiri J (2009) Conocimientos y prácticas sobre la nueva influenza $\mathrm{A}(\mathrm{H} 1 \mathrm{~N} 1)$ en trabajadores de salud y pacientes ambulatorios, Perú (Mayo 2009). Rev Peru Med Exp Salud Pública 26:328-332

14. Abbate R, Di Giuseppe G, Marinelli P, Angelillo IF (2006) Knowledge, attitudes, and practices of avian influenza, poultry workers, Italy. Emerg Infect Dis 12:1762-1765. https://doi.org/ 10.3201/eid1211.060671 
15. Agüero Santagelo F, Nebot Adell M, Pérez Giménez A, López Medina MJ, García Continente X (2011) Attitudes and preventive behaviours adopted during the (H1N1) 2009 influenza virus epidemic in Spain. Rev Esp Salud Publica 85:73-80. https://doi. org/10.1590/s1135-57272011000100009

16. Deng JF, Olowokure B, Kaydos-Daniels SC, Chang HJ, Barwick RS, Lee ML et al (2006) Severe acute respiratory syndrome (SARS): knowledge, attitudes, practices and sources of information among physicians answering a SARS fever hotline service. Public Health 120:15-19. https://doi.org/10.1016/j.puhe.2005.10. 001

17. Grady PA, Gough LL (2014) Self-management: a comprehensive approach to management of chronic conditions. Am J Public Health 104:e25-e31. https://doi.org/10.2105/ajph.2014.302041

18. Chaleshgar-Kordasiabi M, Enjezab B, Akhlaghi M, Sabzmakan I (2018) Barriers and reinforcing factors to self-management behaviour in rheumatoid arthritis patients: a qualitative study. Musculoskeletal Care 16:241-250. https://doi.org/10.1002/msc.1221

19. Veldhuijzen van Zanten JJ, Rouse PC, Hale ED, Ntoumanis N, Metsios GS, Duda JL, Kitas GD (2015) Perceived barriers, facilitators and benefits for regular physical activity and exercise in patients with rheumatoid arthritis: a review of the literature. Sports Med 45:1401-1412. https://doi.org/10.1007/s40279-015-0363-2

20 Oshotse C, Zullig LL, Bosworth HB, Tu P, Lin C (2018) Selfefficacy and adherence behaviors in rheumatoid arthritis patients. Prev Chronic Dis. https://doi.org/10.5888/pcd15.180218

21 Gkrouzman E, Wu DD, Jethwa H, Abraham S (2020) Telemedicine in rheumatology at the advent of the COVID-19 pandemic. HSS J 6:1-4. https://doi.org/10.1007/s11420-020-09810-3

22 Keesara S, Jonas A, Schulman K (2020) Covid-19 and Health care's digital revolution. N Engl J Med. https://doi.org/10.1056/ nejmp2005835

23. Nune A, Iyengar K, Ahmed A, Sapkota H (2020) Challenges in delivering rheumatology care during COVID-19 pandemic. Clin Rheumatol 39:2817-2821. https://doi.org/10.1007/ s10067-020-05312-z

24. England BR, Barber CEH, Bergman M, Ranganath VK, Suter LG, Michaud K (2020) Brief report: adaptation of American College of rheumatology rheumatoid arthritis disease activity and functional status measures for telehealth visits. Arthritis Care Res. https://doi.org/10.1002/acr.24429 (E-pub ahead of print)
25. Gaur PS, Zimba O, Agarwal V, Gupta L (2020) Reporting survey based studies-a primer for authors. J Korean Med Sci. https:// doi.org/10.3346/jkms.2020.35.e398

26 Zucchi D, Tani C, Elefante E, Stagnaro C, Carli L, Signorini V et al (2021) Impact of first wave of SARS-CoV-2 infection in patients with systemic lupus erythematosus: weighting the risk of infection and flare. PLoS ONE. https://doi.org/10.1371/journ al.pone. 0245274

27. Costantino F, Bahier L, Tarancón LC, Leboime A, Vidal F, Bessalah L et al (2021) COVID-19 in French patients with chronic inflammatory rheumatic diseases: clinical features, risk factors and treatment adherence. Joint Bone Spine 88:105095. https:// doi.org/10.1016/j.jbspin.2020.105095

28. Richter JG, Kampling C, Schneider M (2016) Electronic patient reported outcome measures (e-PROMS). In: El Miedany Y (ed) Patient reported outcome measures in rheumatic diseases. Springer, Cham, pp 371-388. https://doi.org/10.1007/978-3-31932851-5_15

29 Hausmann JS, Kennedy K, Simard JF, Liew JW, Sparks JA, Moni TT et al (2021) COVID-19 Global Rheumatology Alliance. Immediate effect of the COVID-19 pandemic on patient health, healthcare use, and behaviours: results from an international survey of people with rheumatic diseases. Lancet Rheumatol. https://doi. org/10.1016/S2665-9913(21)00175-2

30 Zhu W, De Silva T, Eades L, Morton S, Ayoub S, Morand E et al (2021) Rheumatology (Oxford). 60(7):3478-3480. https://doi.org/ 10.1093/rheumatology/keab201

31. Hassen LM, Almaghlouth IA, Hassen IM, Daghestani MH, Almohisen AA, Alqurtas EM et al (2020) Impact of COVID-19 outbreak on rheumatic patients' perceptions and behaviors: a crosssectional study. Int J Rheum Dis 23:1541-1549. https://doi.org/ 10.1111/1756-185x.13959

32 Bhatia A, Kc M, Gupta L (2021) Increased risk of mental health disorders in patients with RA during the COVID-19 pandemic: a possible surge and solutions. Rheumatol Int 41:843-850. https:// doi.org/10.1007/s00296-021-04829-z

Publisher's Note Springer Nature remains neutral with regard to jurisdictional claims in published maps and institutional affiliations.

\section{Authors and Affiliations}

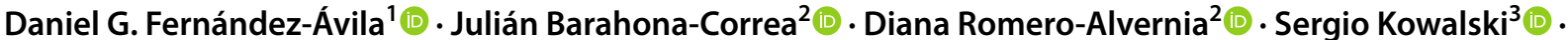

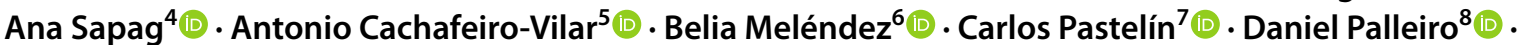

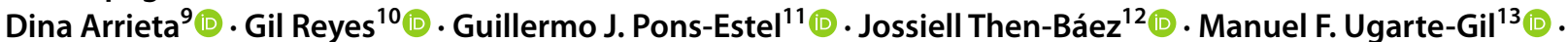

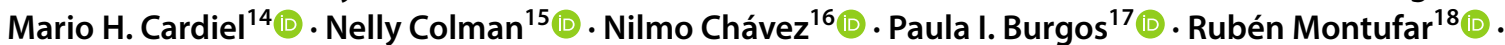 Sayonara Sandino ${ }^{19}$ - Yurilis J. Fuentes-Silva ${ }^{20}$ (E) Enrique R. Soriano ${ }^{21} \mathbb{C}_{0}$}

1 Unidad de Reumatología, Pontificia Universidad JaverianaHospital Universitario San Ignacio, Cra 7 No. 40-62. Piso 7, Bogotá, Colombia

2 Departamento de Medicina Interna, Pontificia Universidad Javeriana-Hospital Universitario San Ignacio, Bogotá, Colombia

3 Universidade Federal do Paraná, Paraná, Brasil

4 Hospital Universitario Japonés, Santa Cruz, Bolivia

5 Pacífica Salud-Hospital Punta Pacífica, Panamá, Panamá

6 Hospital de la Policía Nacional N1 Quito, Quito, Ecuador
7 Instituto Hondureño de la Seguridad Social, Tegucigalpa, Honduras

8 Instituto Nacional de Reumatología del Uruguay, Universidad de la República, Montevideo, Uruguay

9 Hospital México, San José de Costa Rica, San José, Costa Rica

10 Universidad de Ciencias Médicas de la Habana, La Habana, Cuba

11 Centro Regional de Enfermedades Autoinmunes y Reumáticas CREAR, Rosario, Argentina 
12 Hospital Metropolitano de Santiago (HOMS), Santiago, Dominican Republic

13 Hospital Nacional Guillermo Almenara Irigoyen, EsSalud-Universidad Científica del Sur, Lima, Peru

14 Centro de Investigación Clínica de Morelia, Morelia, Mexico

15 Hospital de Clínicas-Universidad Nacional de Asunción, Asunción, Paraguay

16 Instituto Guatemalteco de Seguridad Social-Universidad San Carlos de Guatemala, Guatemala, Guatemala
17 Pontificia Universidad Católica de Chile, Santiago, Chile

18 Consultorio de Especialidades del Instituto Salvadoreño del Seguro Social, San Salvador, El Salvador

19 Instituto Médico Ganna, Managua, Nicaragua

20 Centro Clínico Universitario de Oriente-Universidad de Oriente, Ciudad Bolívar, Venezuela

21 Sección Reumatologia, Servicio de Clinica Médica Hospital Italiano de Buenos Aires-Instituto Universitario Hospital Italiano de Buenos Aires, Buenos Aires, Argentina 